\title{
Ações de Prevenção e Combate aos Incêndios Florestais nas Unidades de Conservação Estaduais do Espírito Santo
}

\author{
André Luiz Campos Tebaldi ${ }^{1}$, Nilton Cesar Fiedler ${ }^{2}$, \\ Ronie Silva Juvanhol ${ }^{3}$, Henrique Machado Dias ${ }^{2}$ \\ ${ }^{1}$ Áreas Protegidas, Instituto Estadual de Meio Ambiente - ES, Vitória/ES, Brasil \\ ${ }^{2}$ Departamento de Ciências Florestais e da Madeira - DCFM, Centro de Ciências Agrárias - CCA, \\ Universidade Federal do Espírito Santo - UFES, Jerônimo Monteiro/ES, Brasil \\ ${ }^{3}$ Programa de Pós-graduação em Ciências Florestais, Departamento de Ciências Florestais e da Madeira - DCFM, \\ Centro de Ciências Agrárias - CCA, Universidade Federal do Espírito Santo - UFES, Jerônimo Monteiro/ES, Brasil
}

\begin{abstract}
RESUMO
Foram avaliadas as condições para prevenção e combate dos incêndios nas Unidades de Conservação (UCs) Estaduais do Espírito Santo. Foram realizadas entrevistas com os gestores das 16 UCs e visitas às mesmas, para análise de documentos, relatórios e planos de manejo. Os incêndios foram caracterizados segundo os grupos de causas e ordenados pelas classes de tamanho: I (0-0,009 ha), II (0,1-4,0 ha), III (4,1-40,0 ha), IV (40,1-200,0 ha) e V (>200 ha). Os menores déficits de pessoal e equipamentos operacionais foram apresentados pelas Unidades de Uso Sustentável. No entanto, a efetividade de gestão das Unidades de Proteção Integral é maior, com uma infraestrutura e pessoal permanente atuando nas mesmas. A maior causa dos incêndios foi representada pela queima para limpeza (20\%), sendo classificados como tamanhos II e III (25\%). Apesar das limitações de pessoal e equipamentos operacionais, as UCs Estaduais possuem condições mínimas para ações de prevenção e combate dos incêndios.
\end{abstract}

Palavras-chave: áreas protegidas, planejamento, políticas públicas.

\section{Actions of Prevention and Combat to Forest Fires in Conservation Units from Espirito Santo state, Brazil}

\begin{abstract}
In this study, we evaluated the conditions for preventing and fighting forest fires in the Conservation Units (CU) of Espirito Santo state, Brazil. We visited the 16 existing CUs in the state. During these visits, we analyzed documents, reports and management plans and conducted interviews with the managers. The fires were characterized by main groups of causes and arranged according to size class: I (0-0.009 ha), II (0.1-4.0 ha), III (4.1-40.0 ha), IV (40.1$200.0 \mathrm{ha}$ ), and V (>200 ha). The Sustainable Use Units showed the lowest deficits of personnel and operating equipment; however, the management effectiveness of the Integral Protection Units is greater, presenting good infrastructure and permanent action of personnel. The major cause of fire was debris burning (20\%) and the most common size classes were II and III (25\%). Despite the limitations in personnel and operational equipment, the CUs hold the minimum conditions required for actions of prevention and combat to forest fires.
\end{abstract}

Keywords: protected areas, planning, public policy. 


\section{INTRODUÇÃO}

Os incêndios florestais geram diversos prejuízos econômicos, ecológicos, paisagísticos e sociais a uma determinada área, principalmente nas mais diversas áreas protegidas existentes no país (Fiedler et al., 2006a). O fogo é o agente com grande potencial para modificar os ecossistemas naturais. Seu regime pode ser caracterizado pelo grau de alteração no ambiente, que vai depender da intensidade, da duração, da frequência e da vulnerabilidade da área afetada pelos incêndios (Cirne \& Scarano, 2001; Tabarelli \& Mantovani, 1999; Castellani \& Stubblebine, 1993).

Quando se trata da ação do fogo sobre as áreas naturais protegidas, destinadas à preservação dos recursos naturais, os efeitos do fogo devem ser criteriosamente avaliados para estabelecer programas de manejo que propiciem a melhor forma de recuperação dos ambientes modificados (Fiedler et al., 2006a; Medeiros \& Fiedler, 2004).

Grande parte das Unidades de Conservação (UCs) no país vem sendo atingida todos os anos pela ocorrência de incêndios (Bonfim et al., 2003). O fogo é considerado como a maior ameaça para a conservação da biodiversidade e dos processos ecológicos em áreas naturais, existentes nos seus limites (Medeiros \& Fiedler, 2004). Os principais agentes causadores de incêndios florestais no Brasil estão associados à atividade desordenada de uso e ocupação do solo, sendo que a melhor forma de reduzir essa ocorrência é por meio de ações educativas de prevenção e conscientização ambiental (Ribeiro, 2004; Santos et al. 2006; Borges et al., 2011).

$\mathrm{O}$ sistema de prevenção e combate dos incêndios florestais em UCs requer investimentos em manutenção de aceiros, campanhas educativas de conscientização, sistema de alerta e fiscalização, comunicação, ferramentas, máquinas e equipamentos de combate, e treinamento de pessoal (Fiedler et al., 2006b; Medeiros \& Fiedler, 2004). No entanto, a eficácia de todo o aparato disponível depende das condições de uso, sendo tal aparato gerenciado e mantido pelas UCs.

Os equipamentos, ferramentas e treinamentos exigidos para prevenção e combate dos incêndios florestais são diferentes dos utilizados no combate aos incêndios urbanos, que devem focar cada situação e tipo de ocorrência (Fiedler et al., 2006b; Castro et al., 2003; Soares \& Germano, 1995). A qualidade das ferramentas de uso manual (enxadas, foices, pás de bico, rastelos, bombas costais), dos equipamentos de apoio (lanternas, apitos, cantis) e dos equipamentos motorizados (motosserras, roçadeiras, motobombas), utilizados pelos brigadistas, deve ser estabelecida como forma de aumentar a eficiência no combate, garantindo maior segurança individual aos envolvidos (Soares, 1984).

A eficiência no combate aos incêndios florestais também depende de avaliação da classe de tamanho da área queimada (Soares, 1988; Santos et al., 2006). Quanto maior a porcentagem de incêndios, maior deverá ser a prevenção administrativa, a variedade de equipamentos e a eficiência no combate (Soares \& Santos, 2002). Para que haja sucesso no controle aos incêndios florestais no país, é necessário que ocorra uma maior concentração de políticas de prevenção, controle e combate das queimadas (Pereira et al., 2004).

Portanto, o objetivo deste estudo foi diagnosticar e avaliar as condições para prevenção e combate dos incêndios florestais em Unidades de Conservação Estaduais do Espírito Santo.

\section{MATERIAL E MÉTODOS}

\section{1. Área de estudo}

O estudo englobou todas as UCs Estaduais administradas pelo Governo do Estado do Espírito Santo (ES). Essas unidades abrangem 18 municípios, totalizando $4.582 \mathrm{~km}^{2}$ de áreas protegidas, de acordo com o instrumento jurídico que estabelece o Sistema Nacional de Unidades de Conservação - Lei n. ${ }^{\circ}$ 9985/00 (Brasil, 2000). As UCs estão distribuídas e categorizadas em $1.160 \mathrm{~km}^{2}$ de Proteção Integral e $3.410 \mathrm{~km}^{2}$ de Uso Sustentável (Figura 1).

\subsection{Delineamento amostral}

Foram realizadas entrevistas semiestruturadas para coleta de dados primários, por meio da aplicação de questionários aos gestores das 16 UCs Estaduais do Espírito Santo. O questionário foi aplicado nos meses de março a junho de 2010, para 


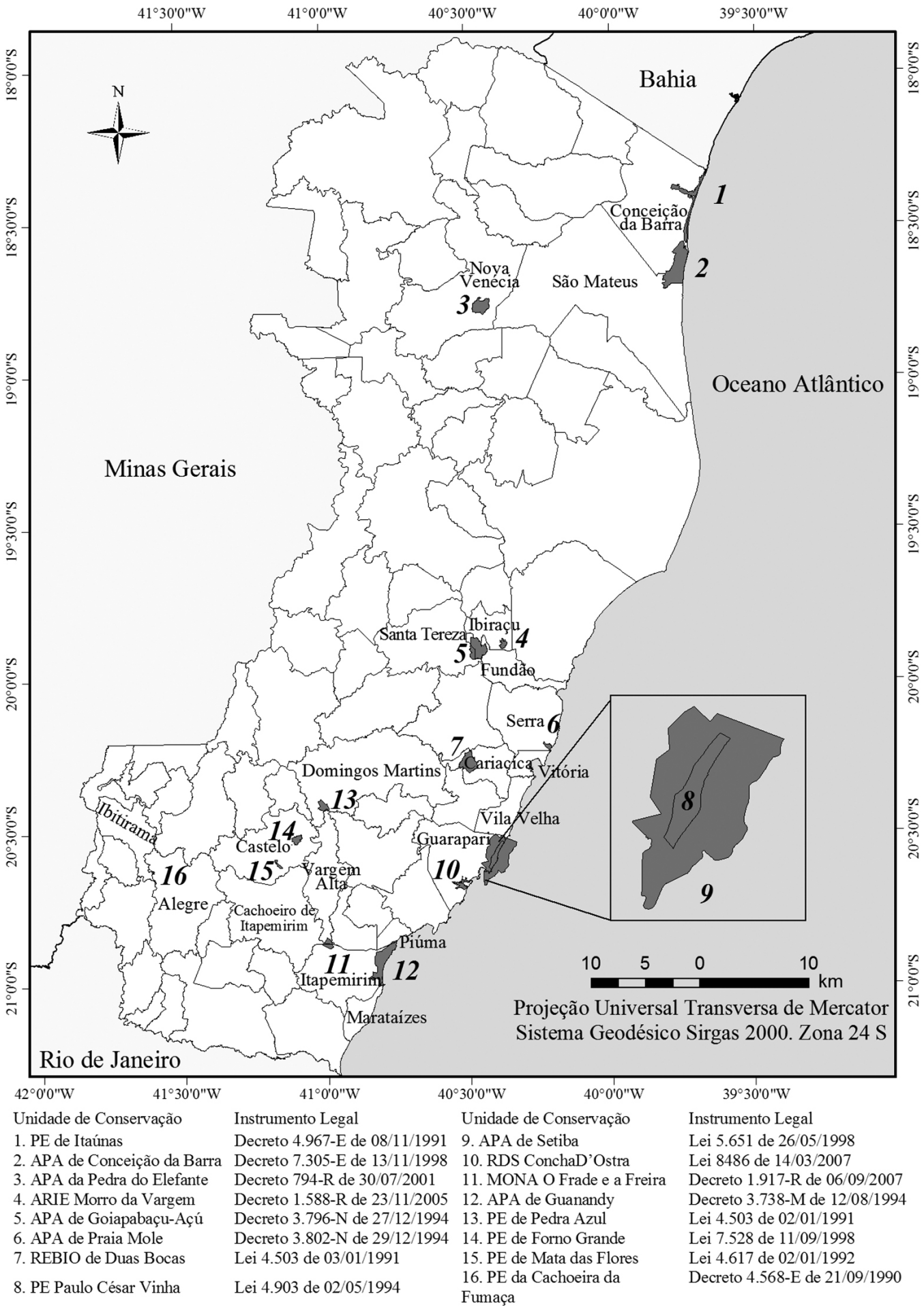

Figura 1. Unidades de Conservação Estaduais do Espírito Santo. (PE: Parque Estadual; APA: Área de Proteção Ambiental; ARIE: Área de Relevante Interesse Ecológico; REBIO: Reserva Biológica; RDS: Reserva de Desenvolvimento Sustentável; MONA: Monumento Natural).

Figure 1. Conservation Units States of the Espirito Santo (PE: State Park; APA: Environmental Protection Area; ARIE: Area of the Relevant Ecological Interest; REBIO: Biological Reserve; RDS: Sustainable Development Reserve; MONA: Natural Monument). 
avaliação das condições de prevenção e combate dos incêndios florestais. Nas visitas às unidades, foi utilizada a técnica de análise de conteúdo, por meio de investigação e análise de documentos, relatórios, planos de manejo e outros materiais disponíveis.

A análise de conteúdo é um procedimento metodológico quantitativo-qualitativo que permite realizar um levantamento da interpretação dos atores envolvidos em relação aos significados presentes em informações de diferentes modalidades, aplicandose, isoladamente ou em conjunto com outras técnicas, ao objeto em estudo (Silva et al., 2005). Acrescenta-se que a análise de conteúdo busca atingir, por meio de técnicas metodológicas, os significados de natureza político-sócio-ambiental.

Para o estudo do levantamento dos dados referentes às condições de prevenção e combate dos incêndios florestais, foi realizado o desenvolvimento de uma pesquisa exploratória e descritiva na coleta e na sistematização dos dados. Para uniformidade na coleta das informações nas UCs, foram considerados apenas os equipamentos e ferramentas em condições de pleno uso em ações de prevenção e combate dos incêndios florestais.

A eficiência na prevenção e no combate dos incêndios florestais deve ser conduzida transversalmente e integrada com variáveis que possam elevar os níveis operacionais da aplicabilidade de pessoal, equipamentos e materiais específicos para ações inerentes ao objeto deste estudo.

O quantitativo de pessoal foi identificado a partir das categorias de profissionais existentes e necessárias para exercer suas funções em cada UC. Os parâmetros adotados para análise do quantitativo de pessoal seguiu uma ordem de efetividade conforme a percepção dos gestores com relação às necessidades previstas nos planos de manejo ou nos demais programas de gestão adotada em cada unidade gestora.

Para a definição dos pesos para cada classe de função, foi considerado o grau de importância do profissional em ações estratégicas de planejamento para prevenção e combate dos incêndios. Os pesos estimados seguiram uma ordem em que os maiores pesos indicam maior importância da classe de função (Tabela 1).

Tabela 1. Distribuição dos pesos estimados por classe de função do recurso de pessoal nas UCs Estaduais.

Table 1. Distribution of weights estimated by class the function the resource personnel in the UCs States.

Classe de Função / Código

Analista de meio ambiente (Pam)

Brigadista $(\mathrm{Pbr})$

Agente técnico (Pat)

Guarda ambiental (Pga)

Ajudante de campo $(\mathrm{Pac})$

Serviços gerais $(P s g)$

Vigilante patrimonial $(P v p)$

Apoio administrativo $(\mathrm{Paa})$

Estagiário (Pest)

Total

A análise de disponibilidade dos recursos de pessoal foi verificada pelo resultado do déficit total (Dt) por UC analisada (Equação 1).

$D t=\left[\begin{array}{l}(D \cdot \text { Pam })+(D \cdot \text { Pbr })+(D \cdot \text { Pat })+(D \cdot \text { Pga })+ \\ +(D \cdot \text { Psg })+(D \cdot \text { Pvg })+(D \cdot \text { Paa })+(D \cdot \text { Pest })\end{array}\right]$

em que: $\mathrm{Dt}=$ Déficit total; $\mathrm{D}=$ Déficit de pessoal por UC, resultante da Equação 2; $P=$ Peso estimado para cada classe de função.

$D=E-N$

em que: $\mathrm{E}=$ Número total de servidores existentes; $\mathrm{N}$ = Número necessário de servidores conforme percepção dos gestores.

As UCs que apresentaram totais iguais ou próximos de 0 (zero) foram identificadas como as que oferecem melhores condições de disponibilidade de pessoal.

Os dados relacionados aos equipamentos operacionais foram distribuídos em tipo de uso: direto e indireto. As classes de equipamentos existentes nas UCs foram estabelecidas de acordo com o tipo de utilização e o grau de importância do equipamento na operacionalização de ações de prevenção e combate dos incêndios florestais (Tabela 2).

A análise de disponibilidade dos equipamentos operacionais foi verificada pelo resultado do Dt por UC analisada (Equação 3). 


$$
D t=\sum_{i=1}^{n}\left(\begin{array}{c}
\mathrm{De}) \\
i
\end{array} \cdot P_{i}\right.
$$

em que: $\mathrm{Dt}=$ Déficit total; $D e=$ Déficit de equipamento no conjunto da UC para cada classe i de equipamento, sendo $i=\{1,2,3,4,5\} ; \mathrm{P}=$ Peso estimado para cada classe de equipamento i.

As UCs que apresentaram o menor déficit total foram identificadas como as que oferecem melhores condições de disponibilidade de equipamento operacional.

Os incêndios florestais registrados nas UCs Estaduais, no período de 2005 a 2009, foram classificados segundo os principais grupos de causas. Estas se agrupam em oito categorias: raios; incendiários; queimas para limpeza; fumantes; operações florestais; estradas de ferro; fogos de recreação, e diversos. Os incêndios foram ordenados de acordo com as classes de tamanho das áreas queimadas, seguindo a classificação padrão do Serviço Florestal dos Estados Unidos (Forest Service, 1956). A Tabela 3 apresenta a classe de tamanho dos incêndios florestais.

Tabela 2. Distribuição dos pesos estimados por classe de equipamento operacional nas UCs Estaduais.

Table 2. Distribution of weights estimated by the class equipment operating in the UC's States.

\begin{tabular}{cllc} 
Item & $\begin{array}{c}\text { Tipo de } \\
\text { uso }\end{array}$ & $\begin{array}{c}\text { Classe de } \\
\text { Equipamento }\end{array}$ & $\begin{array}{c}\text { Peso } \\
\text { Estimado }\end{array}$ \\
\hline 1 & & Operacional externo & 30 \\
2 & Direto & Transporte & 30 \\
3 & & Comunicação & 25 \\
4 & \multirow{2}{*}{ Indireto } & Operacional interno & 10 \\
5 & & Outros & 5 \\
\hline & & Total & 100 \\
\hline
\end{tabular}

Tabela 3. Classes de tamanho dos incêndios florestais. Table 3. Size classes of forest fires.

\begin{tabular}{cc}
\hline Classe & Área do incêndio (ha) \\
\hline I & $0-0,09$ \\
II & $0,1-4,0$ \\
III & $4,1-40,0$ \\
IV & $40,1-200,0$ \\
V & $>200$ \\
\hline
\end{tabular}

Fonte: Adaptado de Forest Service (1956).

\section{RESULTADOS E DISCUSSÃO}

O déficit total de recurso de pessoal nas UCs Estaduais administradas pelo Governo do Espírito Santo variou de zero a 420 pontos, indicando que não ocorre uma uniformidade na distribuição de pessoal de forma a atender às necessidades das UCs (Figura 2). Mais de 50\% das UCs apresentaram déficit total de recurso de pessoal maior do que a média geral (220 pontos). O grupo das UCs de Proteção Integral apresentou maior média de déficit total de pessoal (305,6 pontos), quando comparada com a média nas UCs de Uso Sustentável (220,3 pontos). Dessa forma, sugerem-se maiores investimentos na ampliação do recurso de pessoal para que se minimizem as lacunas existentes de acordo com a classificação adotada no estudo.

Os resultados indicaram que os Parques Estaduais de Itaúnas e Paulo César Vinha apresentam maiores déficits totais de pessoal, 420 e 386 pontos, respectivamente, sendo ambas as UCs de Proteção Integral. A UC de Uso Sustentável representada pela APA de Guanandy apresentou o terceiro maior déficit (380 pontos).

O estudo observou que os menores déficits foram representados pelas UCs de Uso Sustentável. A RDS Concha D’Ostra não apresentou déficit de pessoal e, assim, é indicada como unidade modelo para o Estado do Espírito Santo. As unidades representadas pela APA de Setiba (30 pontos), ARIE Morro da Vargem (67 pontos) e APA Pedra do Elefante (69 pontos) também se destacaram no baixo déficit de pessoal. Já nas UCs de Proteção Integral, o menor déficit total de pessoal foi representado pelo Monumento Natural Frade e Freira (190 pontos).

O comportamento dos déficits totais de recurso de pessoal nas UCs está relacionado com a carência de profissionais em número satisfatório, segundo a percepção dos gestores. Nesse contexto, observouse a inexistência de brigadistas no combate aos incêndios florestais. As falhas existentes no sistema de gestão das áreas protegidas indicam a necessidade de melhorias para evitar a sobrecarga de trabalho aos servidores com atuação direta e indireta nas UCs.

A excelência na gestão pública está relacionada diretamente ao conhecimento da realidade de cada categoria de manejo. As UCs de Proteção 

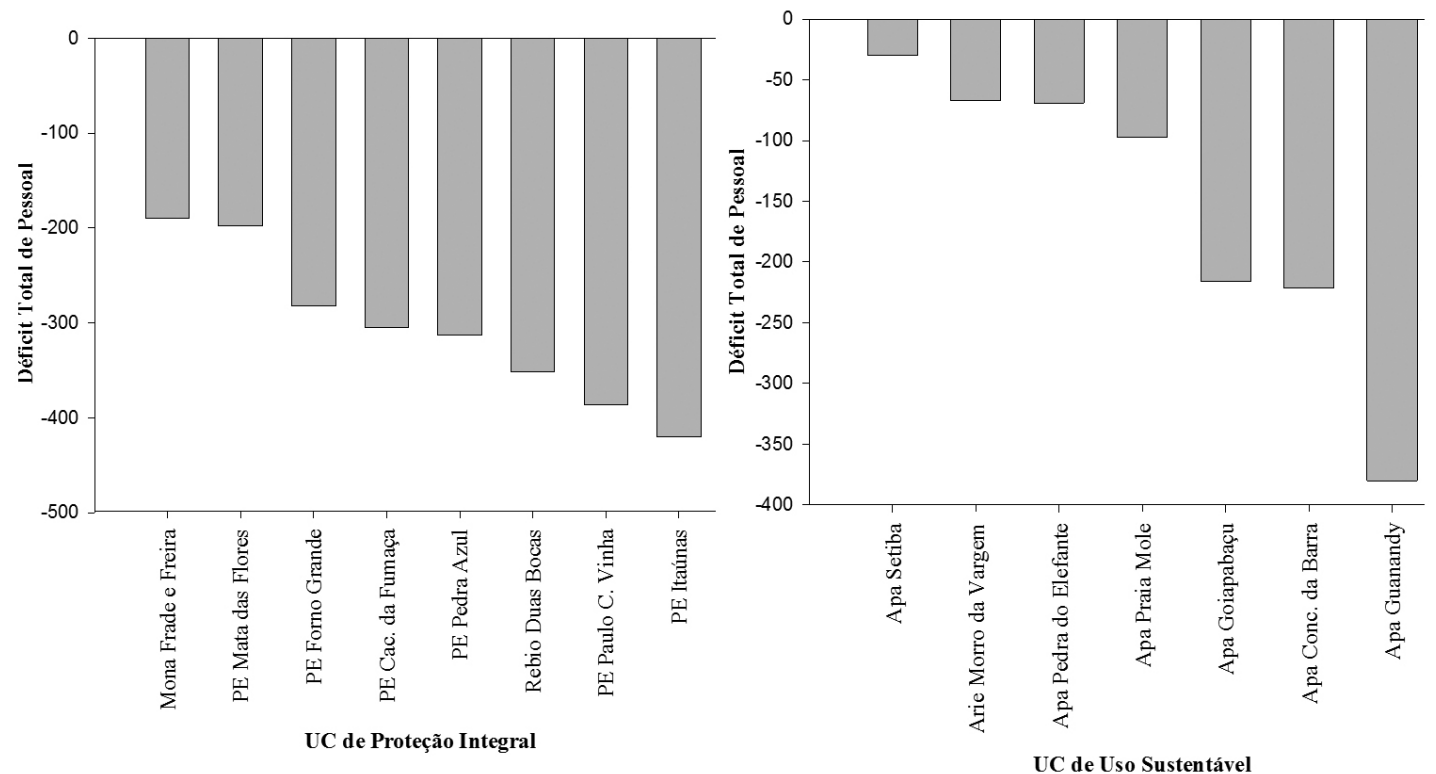

Figura 2. Déficit total de recurso de pessoal nas UCs Estaduais.

Figure 2. Total deficit of resource personnel in the UC's States.

Integral possuem, nos objetivos primários, a proteção da biodiversidade, enquanto as Ucs de Uso Sustentável, a utilização racional dos recursos naturais (Brasil, 2000). Dessa forma, a efetividade de gestão da primeira categoria é maior, com uma infraestrutura e pessoal permanente atuando nas mesmas, em comparação com as UCs de Uso Sustentável, nas quais, em função do uso múltiplo do território, a difícil gestão e a falta de infraestrutura e pessoal permanente são fatores que dificultam sua administração.

As informações relacionadas aos equipamentos operacionais foram levantadas e encontraram-se 42 tipos de equipamentos operacionais com aplicação direta e indireta nas atividades de prevenção e combate dos incêndios florestais (Tabela 4).

Os equipamentos operacionais levantados nas UCs Estaduais apresentaram, em média, o maior déficit em equipamentos de uso operacional interno e comunicação, 11,25 e 7,13 pontos, respectivamente (Figura 3). Observa-se que, aproximadamente, 40\% das UCs Estaduais apresentam déficit superior à média do déficit para os equipamentos operacionais mencionados. O Parque Estadual de Pedra Azul apresentou o maior déficit em equipamentos de uso operacional interno (28 pontos). O grande número de visitantes durante o ano evidencia a necessidade de melhorias em sua estrutura física para a recepção dos turistas e ressalta a importância de palestras educativas para a conscientização do público alvo sobre o tema 'incêndios florestais'. Outras unidades revelaram uma maior deficiência em equipamentos de comunicação, em paralelo com os equipamentos de uso operacional interno, sendo estas: PE Paulo César Vinha (17 pontos) e ARIE Morro da Vargem (16 pontos).

Os déficits totais de equipamentos operacionais nas UCs de Proteção Integral apresentaram déficits superiores aos das unidades de Uso Sustentável, demonstrado na soma dos mesmos (Figura 4). Verifica-se que $50 \%$ das UCs apresentaram déficit total superior à média geral (517,5 pontos) e, nesse cenário, observou-se que $75 \%$ das unidades de Proteção Integral se encontram em igual situação. Essa representação denota uma deficiência acima da média nas UCs em equipamentos operacionais com maior grau de importância para ações de prevenção e combate dos incêndios florestais. Assim, as UCs de Proteção Integral, representadas pelos Parques Estaduais Mata das Flores (890 pontos); Paulo Cesar Vinha (865 pontos), e Pedra Azul (850 pontos) apresentaram o maior déficit total. $\mathrm{O}$ maior déficit total de equipamento em UC de Uso Sustentável 
Tabela 4. Tipos de uso, classificação e relação dos equipamentos identificados nas UCs Estaduais.

Table 4. Types use, classification and relation of equipment identified in the UC's States.

\section{Tipo de uso} Classificação

\section{Equipamentos identificados nas UCs}

GPS (Global Positioning System), câmera fotográfica, motosserra, roçadeira caixa de ferramentas, conjunto motobomba - diesel, conjunto motobom-

Operacional externo ba - gasolina $2 \mathrm{~T}$, conjunto motobomba - gasolina $4 \mathrm{~T}$, grupo gerador, $k$ it com-

Direto bate para camionete, trator, caixa d'água $1000 \mathrm{~L}$, implementos agrícolas, reboque pipa.

Veículos de passeio, utilitários, $4 \times 4$, motocicletas, embarcações com motor de popa.

Telefone, base de rádio, repetidora de rádio, rádio HT, rádio móvel, celular. Material de expediente, computador, impressora, estação meteorológica, esmeril

Indireto de bancada, compressor com kit, mesa de escritório, cadeiras, armário duas portas.

Fax, ventilador, fogão, aspirador de pó, geladeira, máquina de solda, lavadora de alta pressão, ar condicionado.

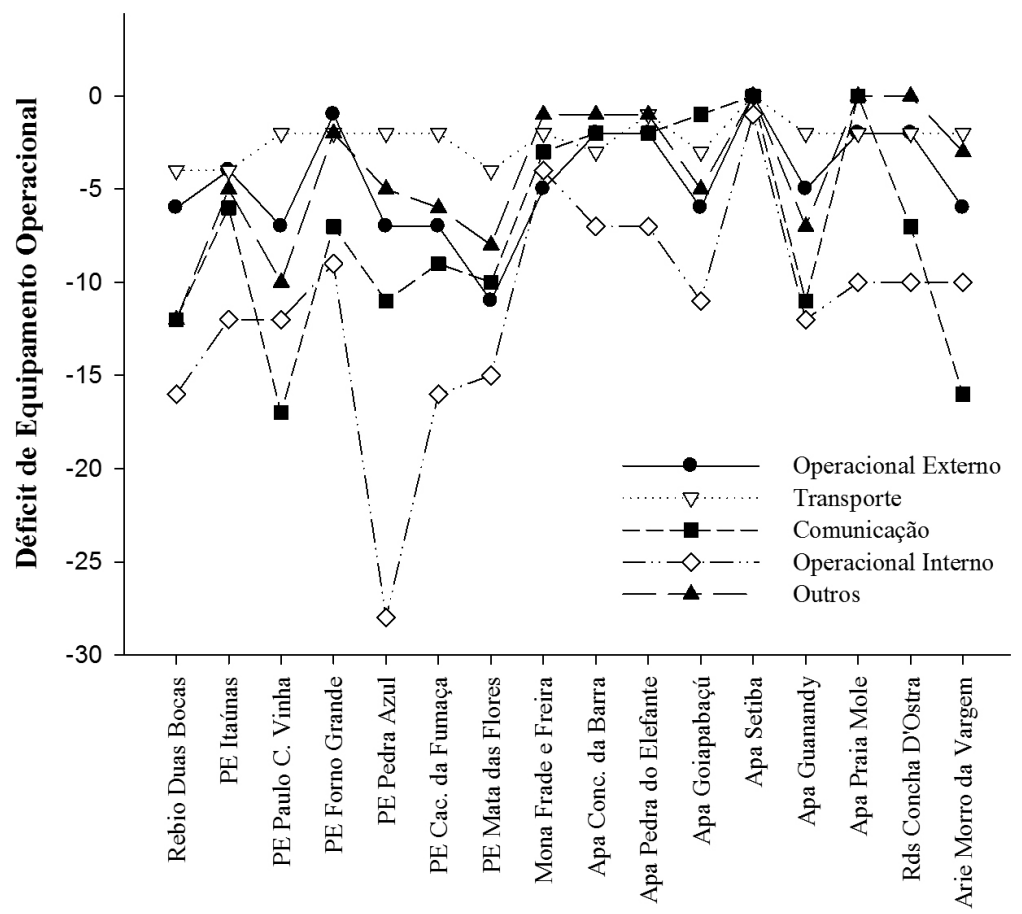

Unidades de Conservação Estaduais

Figura 3. Análise descritiva dos equipamentos operacionais nas UCs Estaduais.

Figure 3. Analysis descriptive of operating equipment in the UC's States.

foi representado pela ARIE Morro da Vargem (755 pontos).

Neste estudo, observou-se que os menores déficits totais foram representados pelas UCs de Uso Sustentável. A APA de Setiba apresentou déficit de equipamento operacional de dez pontos, a APA Pedra do Elefante, 215 pontos, e a APA Praia Mole,
220 pontos. O menor déficit total de equipamento em UC de Proteção Integral foi representado pelo Monumento Natural Frade e Freira (330 pontos).

Muito embora a APA de Setiba tenha apresentado a melhor qualidade entre as demais dessa categoria, deve-se ressaltar que a administração dessa unidade fica estruturada junto ao PE Paulo César Vinha, 

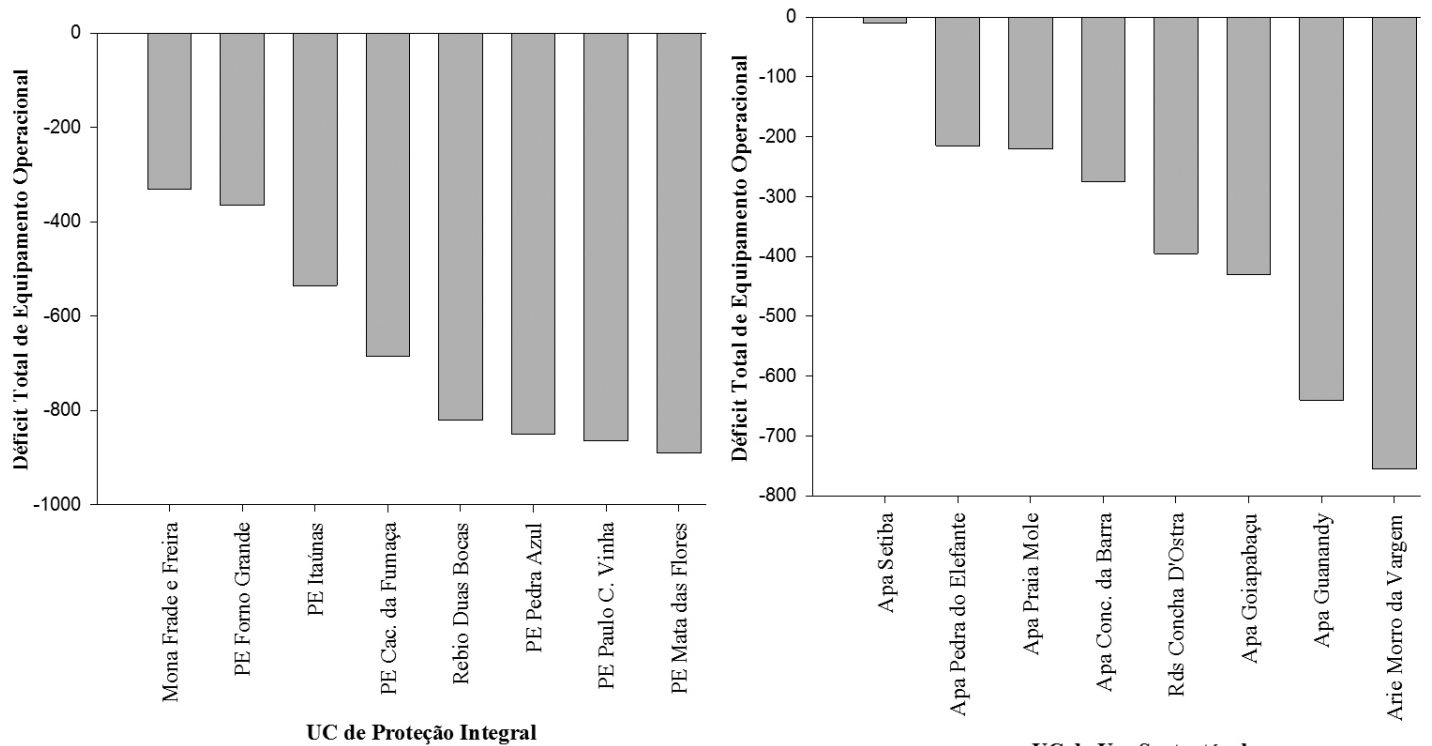

UC de Uso Sustentável

Figura 4. Déficit total de equipamentos operacionais nas UCs Estaduais.

Figure 4. Total deficit operating equipment in the UC's States.

que realiza todo o apoio de infraestrutura e pessoal, envolvendo as ações de vigilância na unidade de uso sustentável.

Uma forma de atenuar ou impedir a ocorrência de incêndios florestais em determinadas áreas está associada à forma de política que a unidade possui, além de como são alocados os recursos e as tecnologias apropriadas, bem como as capacitações relativas à prevenção e ao combate dos incêndios (Tebaldi et al., 2012). Nesse aspecto, as UCs de Proteção Integral apresentam melhores condições de gestão e, por possuir um histórico de atuação com planejamento, direcionam os recursos baseadas em seu plano de manejo, segundo as prioridades das linhas de investimentos. Nas unidades de uso sustentável, por não apresentarem uma estrutura para estabelecer as estratégias de conservação, não se faz planejamento técnico-administrativo; por consequência, não se consegue aplicar os recursos na melhoria da sua gestão.

Fiedler et al. (2006b) afirmam que, para algumas UCs, as brigadas de incêndio apresentam limitações quanto às atividades de controle, principalmente em razão dos problemas relacionados à disponibilidade e ao uso de equipamentos de prevenção e combate. Pereira et al. (2004), a partir de um estudo junto aos brigadistas de um conjunto de UCs no Cerrado, verificaram que suas maiores dificuldades no trabalho estão associadas à carência de infraestrutura, ao patrulhamento insuficiente, à ausência de apoio das populações circunvizinhas e aos frequentes atrasos na prevenção. Assim, em seu conjunto, há ausência de medidas preventivas, o que as torna insuficientes para a redução das áreas queimadas.

No Estado do Espírito Santo, nos últimos cinco anos, foram registrados mais de 2.500 ha de área queimada no interior e no entorno das Ucs, ocasionando redução dos fragmentos florestais e perda da biodiversidade, principalmente em unidades estaduais em regiões litorâneas. Foram registradas 20 ocorrências de incêndios florestais, sendo que as UCs de Proteção Integral apresentaram o maior número de ocorrências (17), em paralelo com as UCs de Uso Sustentável (3). Esse fato é explicado principalmente pela falta de informações nos registros de ocorrências de incêndios nas unidades de uso sustentável, em função da falta de uma equipe técnica permanente que faça o levantamento desses relatórios. Em muitas dessas unidades, a gestão é realizada à distância e, portanto, os planos estratégicos de prevenção e combate dos incêndios tornam-se inconsistentes com a realidade e ineficientes em suas ações.

Os resultados observados revelaram que $85 \%$ das causas dos incêndios são resultantes da ação antrópica e, destes, $40 \%$ foram ocasionados por 
queima para limpeza, $20 \%$ por incendiários, $15 \%$ por fatores diversos e $10 \%$ por fumantes (Figura 5). Os fatores naturais (raios) foram responsáveis por 15\% das causas dos incêndios. No presente estudo, não foi observado o registro de incêndios por recreação, estrada de ferro ou operações florestais.

As principais causas dos incêndios florestais nas UCs de Uso Sustentável estão concentradas em atividades de queima para limpeza (67\%) e incendiários (33\%); nesse sentido, ressalta-se a necessidade de ações prioritárias de políticas públicas associadas à educação e à informação ambiental, em conjunto com novas práticas de manejo do solo, além de ações associadas às atividades de fiscalização e sanções penais para os incendiários, que praticam o ato por interesse próprio. Para efeito deste estudo, os resultados contribuem para elucidar uma política mais participativa e efetiva do Governo Estadual, objeto de competência do Programa Estadual de Prevenção e Combate a Incêndios Florestais - PREVINES (Espírito Santo, 2011).

Nas ocorrências de incêndios em UCs de Proteção Integral, registraram-se queimas para limpeza (35,5\%), incendiários, raios e diversos $(17,5 \%)$, e fumantes (12\%), como causadores dos incêndios florestais. A presença dos grupos 'diversos' e 'fumantes' como causas dos incêndios destaca a necessidade da integração interinstitucional na realização de campanhas educativas para a população no entorno das unidades, pois, em resumo, os incêndios causados por tais grupos são originados pela negligência e pela falta de conscientização das pessoas que têm como prática soltar balões e fogos de artifícios, entre outros motivos, além de lançar pontas de cigarro ou fósforos acesos na vegetação seca. Nesse contexto, verificou-se que as maiores reivindicações dos gestores das UCs de Proteção Integral foram direcionadas a atividades preventivas e educativas de integração com o entorno, sendo estas: REBIO Duas Bocas, PE de Itaúnas, PE de Forno Grande, PE de Pedra Azul e PE Cachoeira da Fumaça.

Os incêndios florestais ocorridos nas UCs Estaduais foram classificados segundo o tamanho, para avaliação da eficiência no combate (Figura 6). Observou-se que $19 \%$ dos incêndios florestais encontram-se na classe I (0-0,09 ha) e 25\% na classe II (0,1-4,0 ha). Soares (1988) identificou o perfil dos incêndios florestais em áreas protegidas no Brasil, no período de1983 a 1987, e observou que $10,5 \%$ das ocorrências encontravam-se na classe I e 41,33\%, na classe II. No período de 1994

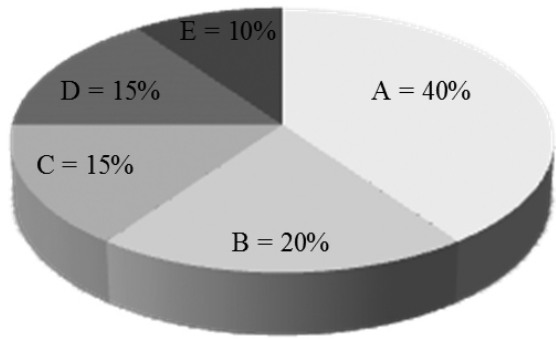

A) Queima para limpeza $\llbracket$ B) Incendiários

C) Raios

D) Diversos

E) Fumantes

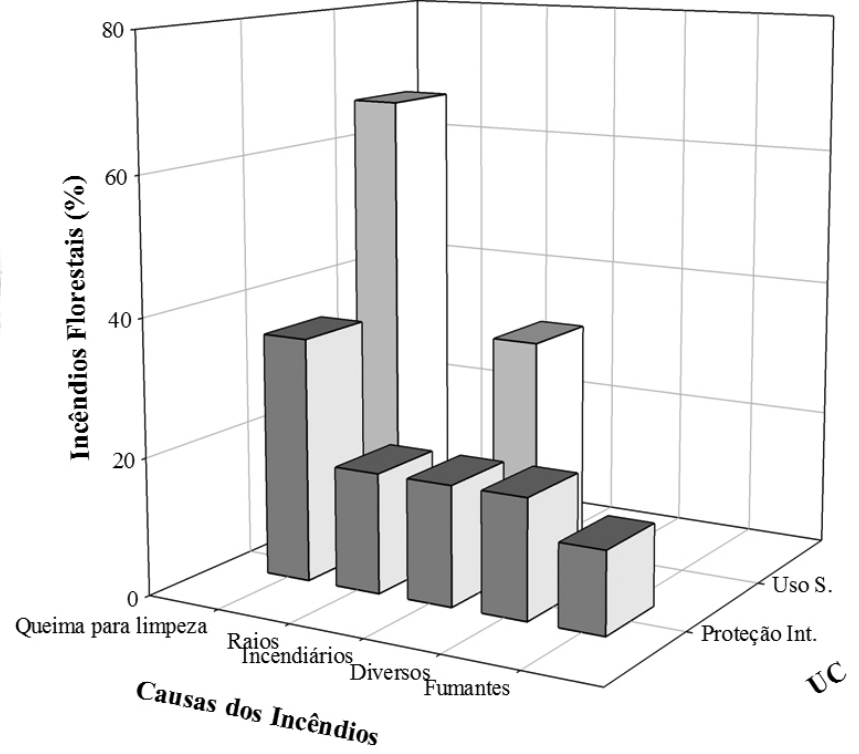

Figura 5. Principais causas dos incêndios florestais nas UCs Estaduais.

Figure 5. Main causes of forest fires in the UC's States. 


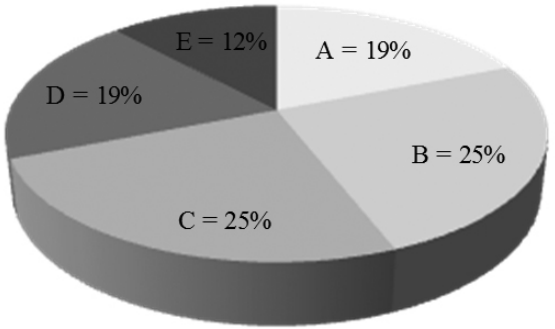
A) I ( 0 - 0,09ha)
B) II $(0,1-4,0 \mathrm{ha})$
C) $\operatorname{III}(4,1-40,0 \mathrm{ha})$
D) IV (40,1 - 200,0ha)
- E) $\mathrm{V}(>200,0 \mathrm{ha})$

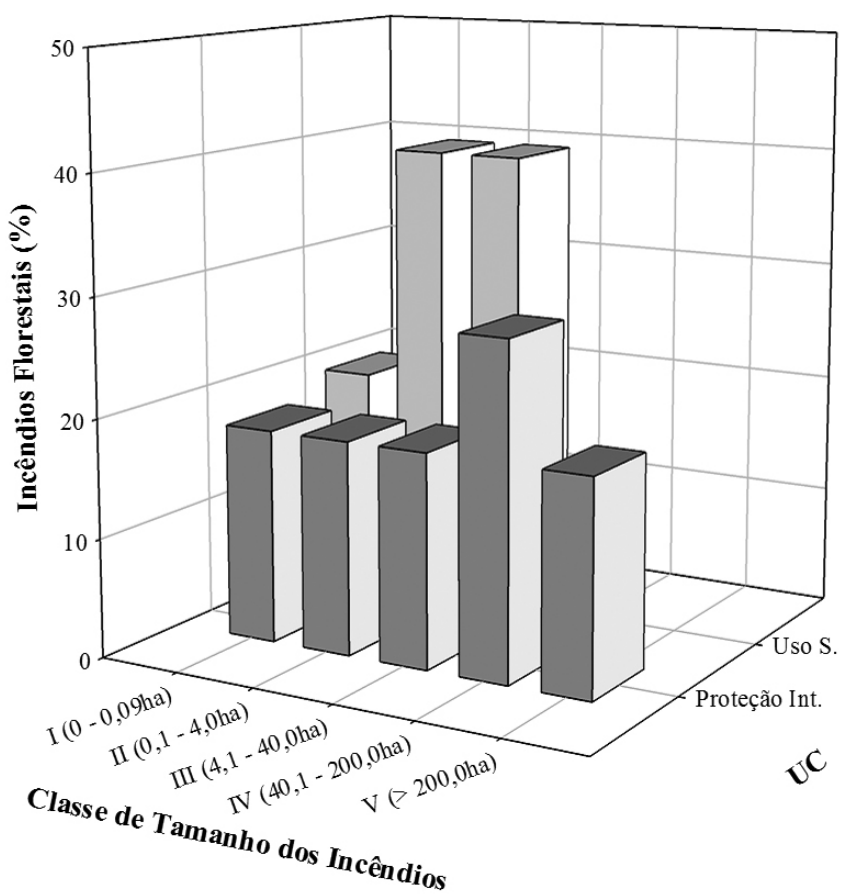

Figura 6. Classes de tamanho das ocorrências dos incêndios nas UCs Estaduais.

Figure 6. Size classes of the occurrences of fires in the UC's States.

a 1997, 23,9\% e 49,1\% dos incêndios representavam as classes I e II, respectivamente (Soares \& Santos, 2002); ainda, no período de 1998 a 2002, 57,15\% dos incêndios estavam na classe I e 33,17\%, na classe II (Santos et al., 2006). Considerando-se que a eficiência de um sistema de combate a incêndios será melhor quanto maior for o número de incêndios com área queimada nas classes I e II, pode-se afirmar que a eficiência no combate aos incêndios florestais nas UCs Estaduais no Espírito Santo é inferior à média nacional de 4,42 ha (Santos et al., 2006). Assim, os resultados encontrados evidenciam a necessidade de aprimoramento do sistema de detecção e mobilização para um efetivo combate, na busca pela redução da duração dos incêndios e, consequentemente, da área queimada nas UCs no Espírito Santo.

Os resultados ainda revelam que $25 \%$ das ocorrências dos incêndios encontram-se na classe III (4,1-40,0 ha), 19\% na classe IV (40,1-200,0 ha) e 12\% na classe V (> 200,0 ha). Nos anos de 2007 e 2008, registraram-se os maiores incêndios no interior das UCs Estaduais, somando mais de 700 ha de áreas afetadas pelo fogo. As duas principais ocorrências foram no PE de Itaúnas, no ano de 2007 (superior a
250 ha), e no PE Paulo Cesar Vinha, em 2008 (superior a 450 ha). Estima-se que as principais causas dessas ocorrências foram originadas por incendiários em virtude de conflitos com o setor privado, no PE de Itaúnas, e relacionadas à urbanização, no PE Paulo C. Vinha.

Nesse contexto, observou-se que as UCs de Proteção Integral apresentaram maiores danos decorrentes dos incêndios florestais, com $28 \%$ das ocorrências na classe IV e 18\% nas demais classes de tamanho. Nas UCs de Uso Sustentável, o sistema de combate aos incêndios florestais apresentou melhor eficiência, com $20 \%$ das ocorrências sendo registradas na classe I e 40\%, na classe II. A classe III foi representada com $40 \%$ das ocorrências. Esse comportamento da classe de tamanho dos incêndios nas UCs Estaduais pode estar relacionado com a causa dos incêndios, em que o uso do fogo para queima para limpeza na renovação da pastagem em grandes áreas agrícolas no Estado é uma atividade comum, realizada em dias que possuem condições favoráveis à propagação do fogo. Dessa forma, uma vez o fogo sem controle, as condições meteorológicas 
(direção e velocidade do vento) e topográficas determinam os efeitos de maior impacto.

Embora haja limitações nos equipamentos operacionais, materiais e ferramentas de uso manual, as UCs Estaduais possuem condições mínimas para ações de combate aos incêndios florestais. Silva (2005) afirma que, mesmo com deficiência de pessoal, infraestrutura e manejo, as unidades de conservação são barreiras efetivas para a ocupação desordenada e predatória dos ambientes naturais. Uma política pública que fortaleça a capacidade de planejar, implementar e manejar apropriadamente essas áreas, em conjunto com a sociedade civil e representantes dos governos em todas as esferas, representa um passo importante nos esforços para proteção do patrimônio natural.

Dessa forma, a alocação de recursos financeiros, materiais e de pessoal é a principal forma de estruturação, planejamento e gestão das UCs Estaduais e também uma estratégia de proteção dos recursos naturais em longo prazo. Assim, o território da unidade que faz parte do processo de planejamento ambiental se concretizará com prioridades, em que se estabelecerão normas de uso baseadas nas condições locais.

\section{CONCLUSÕES}

No Estado do Espírito Santo, as Unidades de Uso Sustentável se apresentaram em melhores condições, com recurso de pessoal e equipamentos operacionais, em relação às Unidades de Proteção Integral.

A metodologia para avaliação dos déficits de pessoal e equipamentos nas Unidades de Conservação do Estado do Espírito Santo é eficiente, pois mostra uma relação direta entre os maiores déficits e as maiores classes de tamanho de ocorrência de incêndios florestais.

As principais causas dos incêndios florestais nas UCs Estaduais do Espírito Santo são ocasionadas por queima para limpeza e tal fato caracteriza o comportamento apresentado do tamanho dos incêndios: uma área queimada nos limites das classes II e III para as UCs de Uso Sustentável e, na classe IV, para as UCs de Proteção Integral.

O combate aos incêndios nas UCs Estaduais no Espírito Santo é ineficiente e, portanto, evidencia a necessidade de aprimoramento do sistema de detecção e mobilização aos incêndios.

O planejamento das UCs Estaduais do Espírito Santo, em que o plano de manejo e o plano de prevenção e combate dos incêndios florestais são ferramentas básicas para sua delimitação, é indicado para o reconhecimento do uso múltiplo do território para uma efetiva estruturação e gestão das unidades.

\section{AGRADECIMENTOS}

Ao Governo do Estado do Espírito Santo, por meio do Instituto Estadual de Meio Ambiente e Recursos Hídricos (IEMA); aos gestores das UCs Estaduais do Espírito Santo; ao Programa de PósGraduação em Ciências Florestais da Universidade Federal do Espírito Santo (UFES), e ao CNPq, à CAPES e à FAPES, pelo apoio financeiro.

\section{STATUS DA SUBMISSÃO}

Recebido: $21 / 06 / 2013$

Aceito: 12/09/2013

Publicado: 31/12/2013

\section{AUTOR(ES) PARA CORRESPONDÊNCIA}

\section{Nilton Cesar Fiedler}

Departamento de Ciências Florestais e da Madeira - DCFM, Centro de Ciências Agrárias - CCA, Universidade Federal do Espírito Santo - UFES, CEP 29550-000, Jerônimo Monteiro, ES, Brasil e-mail: fiedler@pq.cnpq.br

\section{REFERÊNCIAS}

Bonfim VR, Ribeiro GA, Braga GM. Diagnóstico do uso do fogo no entorno do Parque Estadual da Serra do Brigadeiro, MG. Revista Árvore 2003; 27(1): 87-94. http://dx.doi.org/10.1590/S0100-67622003000100012

Borges TS, Fiedler NC, Dos Santos AR, Loureiro EB, Mafia RG. Desempenho de alguns índices de risco de incêndios em plantios de eucalipto no norte do Espírito Santo. Floresta e Ambiente 2011; 18(2): 153-15. http:// dx.doi.org/10.4322/floram.2011.033

Brasil. Lei $\mathrm{n}^{\circ}$ 9.985, de 18 de julho de 2000. Diário Oficial da República Federativa do Brasil, Brasília DF (2000 jul. 18). 
Castellani TT, Stubblebine WH. Sucessão secundária inicial em mata tropical mesófila, após perturbação por fogo. Revista Brasileira de Botânica 1993; 16(2): 181203.

Castro CF, Serra G, Parola J, Reis J, Lourenço L, Correia S. Combate a incêndios florestais. 3. ed. Escola Nacional de Bombeiros: Sintra; 2003.

Cirne P, Scarano FR. Resprouting and growth dynamics after fire of the clonal shrub Andiralegalis (Leguminosae) in a Sandy coastal plain in south-eastern Brazil. Journal of Ecology 2001; 89: 351-357. http://dx.doi.org/10.1046/ j.1365-2745.2001.00557.x

Espírito Santo. Decreto no $2.704-\mathrm{R}$, de 17 de março de 2011. Diário Oficial do Estado do Espírito Santo, Vitória, (2011 mar. 18).

Fiedler NC, Merlo DA, Medeiros MB. Ocorrência de incêndios florestais no Parque Nacional da Chapada dos Veadeiros, Goiás. Ciência Florestal 2006a; 16(2): 153-161.

Fiedler NC, Rodrigues TO, Medeiros MB. Avaliação das condições de trabalho, treinamento, saúde e segurança de brigadistas de combate a incêndios florestais em unidades de conservação do Distrito Federal - Estudo de Caso. Revista Árvore 2006b; 30(1): 55-63. http:// dx.doi.org/10.1590/S0100-67622006000100008

Forest Service. Glossary of terms used in forest fire control. United States: Department Agriculture Handbook 104; 1956.

Medeiros MB, Fiedler NC. Incêndios florestais no Parque Nacional da Serra da Canastra: desafios para a conservação da biodiversidade. Ciência Florestal 2004; 14(2): 157-168.

Pereira CA, Fiedler NC, Medeiros MB. Análise das ações de prevenção e combate aos incêndios florestais em unidades de conservação do Cerrado. Floresta 2004; 34(2): 95-100.

Ribeiro GA. Estratégias de prevenção contra os incêndios florestais. Floresta 2004; 34(2): 243-247.

Santos JF, Soares RV, Batista AC. Perfil dos incêndios florestais no Brasil em áreas protegidas no período de 1998 a 2002. Floresta 2006; 36(1): 93-100.

Silva CR, Gobbi BC, Simão AA. O uso da análise de conteúdo como uma ferramenta para a pesquisa qualitativa: descrição e aplicação do método. Organizações rurais \& Agroindustriais 2005; 7(1): 7081. http://dx.doi.org/10.1111/j.1523-1739.2005.00707.x

Silva M. The brazilian protected areas program. Conservation Biology 2005; 19(3): 608-611.

Soares RM, Germano JOG. Estratégias de treinamento e capacitação de brigadas de incêndios. In:Anais de Instituto de Pesquisas Florestais; 1995.p.48-49.

Soares RV. Perfil dos incêndios florestais no Brasil em 1983. Brasil Florestal 1984; 58: 31-42.

Soares RV. Perfil dos incêndios florestais no Brasil de 1984 a 1987. Floresta 1988; 18(12): 94-121.

Soares RV, Santos JF. Perfil dos incêndios florestais no Brasil de 1994 a 1997. Floresta 2002; 32(2): 219-232.

Tabarelli M, Mantovani W. A regeneração de uma floresta tropical Montana após corte e queima (São Paulo-Brasil). Revista Brasileira de Biologia 1999; 59(2): 239-250. http://dx.doi.org/10.1590/S003471081999000200008

Tebaldi ALC, Fiedler NC, Dias HM. Vulnerability and Management of Protected Areas from the State of Espirito Santo, Brazil. Floresta e Ambiente 2012; 19(3): 267-276. http://dx.doi.org/10.4322/floram.2012.032 